
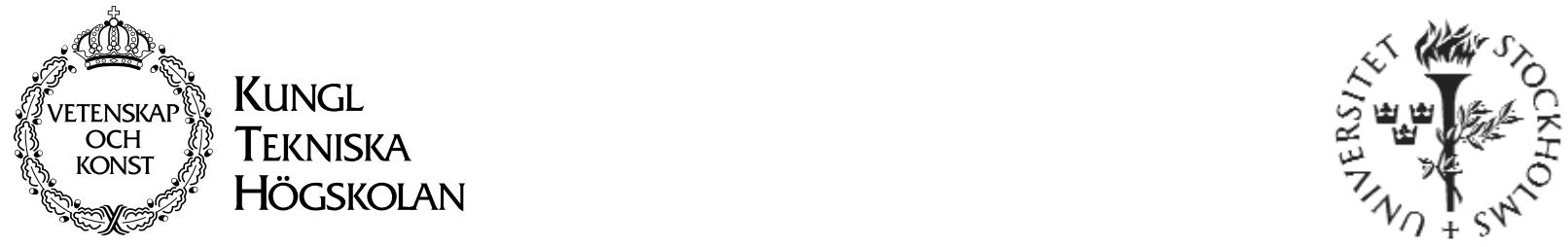

\title{
Work Environment and Computer Systems Development.
}

Jan Gulliksen and Bengt Sandblad 
Författare: Jan Gulliksen and Bengt Sandblad

Work Environment and Computer Systems Development.

Report number: CID-133

ISSN number: ISSN 1403-0721 (print) 1403-073X (Web/PDF)

Publication date: August 2001

E-mail of author: jan.gulliksen@hci.uu.se

URL of author: http://cid.nada.kth.se

\section{Reports can be ordered from:}

CID, Centre for User Oriented IT Design

NADA, Deptartment of Numerical Analysis and Computer Science

KTH (Royal Institute of Technology)

SE-100 44 Stockhom, Sweden

Telephone: + 46 (0) 87909100

Fax: + 46 (0) 87909099

E-mail: cid@nada.kth.se

URL: http://cid.nada.kth.se 


\title{
WORK ENVIRONMENT AND THE DEVELOPMENT OF INFORMATION SYSTEMS
}

\author{
J. Gulliksen ${ }^{\mathrm{a}, \mathrm{b}}$ and B. Sandblad ${ }^{\mathrm{a}}$ \\ ${ }^{\mathrm{a}}$ Department of Human Computer Interaction, Information Technology, Uppsala University, \\ P.O. Box 337, SE-751 05 Uppsala, Sweden \\ ${ }^{\mathrm{b}}$ Centre for User Oriented IT-design (CID), Royal Institute of Technology, Stockholm, Sweden
}

\begin{abstract}
Investigations indicate that different types of work environment problems in computer supported work are constantly increasing. Most efforts to improve the work environment are focused on physical or psychosocial aspects, since these are easier to measure and provide efficient solutions to. Mental workload and cognitive problems are of a more complex nature, and are therefore more seldom studied and solved. Solutions to work environment problems are usually applied to already constructed work situations through health programs, education, reorganizations, etc. The problems are seldom prevented by methods applied early in the systems development process, i.e. before the artifacts have been designed and implemented. This, and the following papers of the session, will focus on the need to integrate different interdisciplinary methods in the analysis, design and evaluation of computerized work situations, aimed at preventing work environment problems.
\end{abstract}

\section{INTRODUCTION}

1.1 Work environment problems in computer supported work

Despite the increasing interest in work environment problems, we know that problems with badly designed an inefficient computer systems in working life are increasing. Statistics from Sweden show that in $199965 \%$ of all Swedish employed used a computer tool in their everyday work. More then $30 \%$ used computer systems during more then $50 \%$ of their working day. Recent investigations also show that up to $70 \%$ of all employed in office and case handling work, where computer systems are used during most of the day, report daily problems related to stress, physical and mental load.

A class of work environment problems that becomes especially important to consider in intensively computer-supported work are the cognitive work environment problems. With cognitive work environment problems we mean when properties of the work environment hinder the persons performing the work to efficiently use their skills. These hindrances, i.e. the cognitive work environment problems, are often associated with the design of the information system. If the system has an inappropriate functionality, a bad user interface or if the user does not have the right competencies such problems occur.

Most activities aimed at improving the work environment for professionals in intensively computer supported work situations are adopted very late, i.e. when physical or psychosocial problems already have been manifested and reported. We believe that it is both important and feasible to address potential work environment problems already during the development process. We know, however, that organizations already have difficulties in addressing aspects related to the usability of artifacts under development. If we add the challenge to also include work environment aspects in the systems requirements, the task will most often become impossible in practice.

\subsection{Research goals}

In our research, some modern software development models and tools have been studied and new requirements concerning their properties have been specified, in order to improve them. Some of the most 
important additional factors that must be treated by the software development tools are: modeling of future work processes, integrated development of work organization and IT support systems, user interface design that can reduce mental work load and control of the work processes, education and training of future users in order to prepare them for the new technical systems and for the new work situations.

\section{INTEGRATION AND THE DEVELOPMENT PROCESS}

2.1. Usability and work environment requirements

The major goal for every professional involved in user interface development is, presumably, to develop systems that are usable. This should be especially important for user interface designers, as their efforts have a most immediate effect on system usability. We use the term usability as defined in the ISO 9241 standards on "Software ergonomics for office work with visual display terminals (VDTs)" Part 11 Guidance on usability:

"Usability is the extent to which a product can be used by specified users to achieve specified goals with effectiveness, efficiency, and satisfaction in a specified context of use". [ISO, 1998]

Several researchers have put the blame for the lack of usability on the users themselves not requiring sufficient usability in the process of ordering or purchasing the systems [Thimbleby, 1999]. Studies of requirement specifications with respect to usability and work environment aspects show that these requirements (however, in practice very few) were not particularly useful in the development process, mainly because they were not concrete and related to a measurable entity. Directed efforts to help the users specify measurable requirements on usability and the work environment resulted in very few measurable requirements, and of these most of them related to efficiency.

\subsection{Integrated methods}

Integrated design refers to methods in which all aspects of usability evolve together [Gould, Boies \& Ukelson, 1997]. Our view on integrated design is a further elaboration of Leavitt's [1958] integration of organization, work, competence and technology to involve all aspects that can influence the development of a computerized work environment, especially work environment aspects that are often ignored.

We have been experimenting with integrated methods by applying interdisciplinary cooperation in real development settings, e.g.:

- Integrated analysis - Experts in organizational development, knowledge production processes, work environment and human computer interaction performs semi-structured "observation-interviews" in a real work setting in parallel sessions. Immediately after the sessions the experts document and prioritize findings according to their relevance and the degree of seriousness of the discovered problems.

- Integrated design - Experts in systems development, usability, human computer interaction, organizational development, knowledge production processes, and work environment participate in cooperative design sessions. In these sessions groups of users design prototypes in parallel sessions mediated by the experts. They later reconvene to present their different design solutions for further elaboration. The experts present and report their observations back to the development team.

- Integrated evaluation - A usability inspection is performed in which we use the various multidisciplinary competencies in the evaluation process.

- All preliminary results point to the fact that integrated design requires the introduction of the specific competencies into the actual development work. The complexity of all aspects relating to the health 
and well-being of a worker using a computer artifact cannot be introduced without bringing in experts from these different areas.

\subsection{A user-centered development process}

Most systems development work is today performed according to some more or less industrial model. The purchasing organization is specifying their requirements on the system as far as their knowledge allows. Here requirements related to usability are rare. The development organization is doing its best in trying to interpret the requirements and transforming them into a functioning system as efficiently as possible. In this process user involvement is normally avoided to a large extent in order to minimize project risks, repeatedly modified requirements, and time consuming iterations. However, this often gives a bad outcome, because active user involvement is a necessity for applying user centered design.

For an organization to adopt new procedures for their systems development it is essential that the development model is initiated and controlled by the organization itself. To our knowledge, no one has ever successfully deployed a user-centered development methodology towards an organization that is not appreciative. We have earlier performed reengineering work within a large governmental in-house development organization with successful results [Gulliksen \& Göransson, 2001]. With our help they defined their ways of looking upon and performing user-centered design and to initiate further development of their user-centered design process by themselves.

The next step is to include such experiences in the used development methodology. Normally the standard development models available do not fulfill necessary requirements with regard to being user-centered. We have made some studies on the benefits of commercial system development methodologies such as the Rational Unified Process (RUP) and found severe problems with the process from a user-centered design perspective [Gulliksen, Göransson \& Lif, 2001].

A conclusion is, that if we want to be able to consider work environment problems, development of competencies, work organization etc. in the development process, we must make sure that additional methodological steps for this are included in the development model used.

2.4. Usability designers to improve the user centered process Usability champions [Gould et al. 1997] are one way to introduce HCI knowledge into the development work from within. We introduced the concept of the usability designer as a specific competence to keep the development process user centered [Göransson \& Sandbäck, 1999]. We have seen examples where HCI researchers have apprenticed like usability designers and we have also acted towards organizations that have employed their own usability designer as a resource in the development team. The best results can be reached, as far as we have seen, when the usability designer works as a mentor inside an organization that consciously works towards a user centered design methodology.

Due to the complexity of the task, the size of the organizations and the limited authority of the usability designer in the organizations, we have so far not been able to have the usability designer to be responsible for the work environment aspects as well. Work environment professionals requires rather different skills and methods, why it would not be realistic to combine all usability and work environment responsibilities in one person.

There is, however, a risk that the organization can take the usability designer as a hostage, not giving the role the essential mandate to perform and control the required activities, but blaming the role for potential usability and work environment failures. In our case, this has been overcome by the connection the usability designer has with the researchers, but this cannot be the solution under normal development conditions. It is therefore essential that this role is given enough mandate in the development organization, so that the rest of the team has to follow the advice and guidelines. 
2.5 Development of user competencies

Normally users are offered training in the use of the new tools developed, i.e. the handling of the new information systems. This is of course important, but in practice not satisfactory performed. It proves to be more important to concentrate on developing skills and to train the users in how to perform the new work procedures. This includes the handling of the tools, but more important also how to work efficiently in the new work setting. It is our experience that too little attention is given to the design of the new work procedures and what the differences are between the old procedures and the new. If the new work procedures are performed according to old traditions and standards, this will result in inefficient use of the new information systems, something that in its turn will result in increased mental workload and stress.

2.6 Other aspects to consider in the development process

There are numbers of other important aspects related to usability and the work environment that should be considered during systems development. And appropriate methodological modules must be included in the development process to address these issues. Some of these aspects will be further addressed in the following papers, and we will here only underline one such aspect: the design of the new work organization. Very often the structure of the new organization that will be the result of the development process is not consciously designed, but it rather appears. The design of the organization must be considered during the entire systems development process. It must be designed, visualized in the prototypes, tested, evaluated and repeatedly refined according to the work activity requirements as they develop and evolve during the system development process.

\section{CONCLUSIONS}

There is a need to increase the awareness and maturity when it comes to consider usability aspects and particularly work environment issues already in the system development process. To be able to do this efficiently the following activities are needed:

- Increase the awareness both among the developers and the development organization as well as among the users and user organizations.

- Improve competencies for the user organizations to order systems based on requirements concerning usability and work environment aspects.

- Complement traditional software development models with methods and tools to consider work environment aspects.

We believe that it is most efficient to put the efforts into the development process instead of trying to solve usability problems in products and systems. In this way the usability and work environment problems can be prevented instead of solved when they are already manifested. The following are some of the observations that we have made in our applied research:

- Skills and knowledge development. Education programs for developers can be successful if they repeatedly are directed towards all participants in the development teams. The responsibility for usability and work environment aspects must be given to experts and not as additional tasks to developers with other basic skills and responsibilities. Organizational mentors can support individual developers and teams.

- Process improvement. Existing development processes do not give enough support for the integration of the required competencies in the development work. One solution is to provide detailed process guidelines for user-centered design and criteria for the selection of users in the development process.

- Good examples. Despite all existing methods and tools for improving the work environment and the usability of the computer support, what really has an effect in practice is the good examples that we 
can study and use as an inspiration. Unfortunately there are rather few good examples out in "real life" development of information systems.

\section{ACKNOWLEDGEMENTS}

This research has been financed by the Swedish Council for Working Life, the Swedish National Tax Board and the Swedish National Social Insurance Board.

\section{REFERENCES}

1. International Organization of Standardization (1998). ISO 9241 Ergonomic requirements for office work with visual display terminals (VDTs) Part 11 - Guidance on usability. (International standard).

2. H. Thimbleby.(2000) On discerning users. In J. Gulliksen, A. Lantz \& I. Boivie (eds.) How to make user centered design usable. Technical report TRITA-NA-D0006, CID-72. Available at: http://www.nada.kth.se/cid/pdf/cid_72.pdf

3. J.D. Gould, S.J. Boies, J. Ukelson (1997) How to Design Usable Systems. In Helander, M., Landauer, T.K., Prabhu, P. (eds.) Handbook of Human-Computer Interaction, 2nd ed. pp. 231-254, Elsevier Science B.V.

4. H.J. Leavitt (1958) Managerial Psychology. University of Chicago Press, Ltd. London.

5. J. Gulliksen \& B. Göransson (2001) Reengineering the systems development process for usercentered design. In Michitaka Hirose (ed.) Proceedings of INTERACT 2001, Tokyo, Japan. IOS Press

6. J. Gulliksen, B. Göransson \& M. Lif (2001) A User centered Approach to Object-Oriented User Interface Design. In M. van Harmelen (ed.) Designing Interactive Systems: Object Modeling and User Interface Design. Addison Wesley Longman.

7. B. Göransson \& T. Sandbäck (1999) Usability designers improve the user-centred design process. In Proceedings for INTERACT'99, Edinburgh, UK. 